\title{
Article
}

\section{IPA1 Negatively Regulates Early Rice Seedling Development by Interfering with Starch Metabolism via the GA and WRKY Pathways}

\author{
Yonggang He (D), Menghao Zhu, Zhihui Li, Shan Jiang, Zijun He, Shuang Xu, Xiangsong Chen, Zhongli Hu \\ and Zhihong Zhang *
}

check for updates

Citation: He, Y.; Zhu, M.; Li, Z.; Jiang, S.; He, Z.; Xu, S.; Chen, X.; Hu, Z.; Zhang, Z. IPA1 Negatively Regulates Early Rice Seedling Development by Interfering with Starch Metabolism via the GA and WRKY Pathways. Int. J. Mol. Sci. 2021, 22, 6605. https://doi.org/10.3390/ ijms22126605

Academic Editor: Yong-Gu Cho

Received: 10 May 2021

Accepted: 16 June 2021

Published: 20 June 2021

Publisher's Note: MDPI stays neutral with regard to jurisdictional claims in published maps and institutional affiliations.

Copyright: (c) 2021 by the authors. Licensee MDPI, Basel, Switzerland. This article is an open access article distributed under the terms and conditions of the Creative Commons Attribution (CC BY) license (https:/ / creativecommons.org/licenses/by/ $4.0 /)$.
State Key Laboratory of Hybrid Rice, College of Life Sciences, Wuhan University, Wuhan 430072, China; whuhyg@whu.edu.cn (Y.H.); 2012202040102@whu.edu.cn (M.Z.); 2020102040041@whu.edu.cn (Z.L.); 2020202040061@whu.edu.cn (S.J.); 18986642398@163.com (Z.H.); 2020202040067@whu.edu.cn (S.X.); chen.xs@whu.edu.cn (X.C.); huzhongli@whu.edu.cn (Z.H.)

* Correspondence: zzh@whu.edu.cn; Tel.: +86-138-7149-1559
Abstract: Ideal Plant Architecture 1 (IPA1) encodes SQUAMOSA PROMOTER BINDING PROTEINLIKE 14 (SPL14) with a pleiotropic effect on regulating rice development and biotic stress responses. To investigate the role of IPA1 in early seedling development, we developed a pair of IPA1/ipal-NILs and found that seed germination and early seedling growth were retarded in the ipa1-NIL. Analysis of the soluble sugar content, activity of amylase, and expression of the $\alpha$-amylase genes revealed that the starch metabolism was weakened in the ipa1-NIL germinating seeds. Additionally, the content of bioactive gibberellin (GA) was significantly lower than that in the IPA1-NIL seeds at $48 \mathrm{~h}$ of imbibition. Meanwhile, the expression of GA synthesis-related gene OsGA20ox1 was downregulated, whereas the expression of GA inactivation-related genes was upregulated in ipa1-NIL seeds. In addition, the expression of OsWRKY51 and OsWRKY71 was significantly upregulated in ipa1-NIL seeds. Using transient dual-luciferase and yeast one-hybrid assays, IPA1 was found to directly activate the expression of OsWRKY51 and OsWRKY71, which would interfere with the binding affinity of GA-induced transcription factor OsGAMYB to inhibit the expression of $\alpha$-amylase genes. In summary, our results suggest that IPA1 negatively regulates seed germination and early seedling growth by interfering with starch metabolism via the GA and WRKY pathways.

Keywords: rice (Oryza sativa L.); seed germination; IPA1/OsSPL14; gibberellin (GA); WRKY

\section{Introduction}

Seed germination is a complex and diverse process that plays an important role in ensuring the continuity of life. Generally, germination starts with water uptake and the reactivation of diverse metabolism processes in the quiescent seed, followed by emergence of the radical and coleoptile [1]. In rice, many nutrients accumulate in the endosperm during seed maturation. As germination progresses, these reserves are hydrolyzed into metabolizable nutrients by a series of hydrolases, then absorbed by the scutellum epithelium and transported to the embryonic axis [2,3]. Thus, the efficient degradation and utilization of seed reserves are particularly important to seed germination and early seedling development.

Starch is the major reserve in rice seed that provides a major carbon source for generating energy and metabolites. During seed germination and early seedling growth, starch is degraded by the concerted action of various hydrolases, including $\alpha$-amylase, $\beta$-amylase, debranching enzyme, and $\alpha$-glucosidase [4]. Among them, $\alpha$-amylase is the most abundant hydrolase in rice. It catalyzes the hydrolysis of $\alpha$-1,4-glucosidic bonds of starch at random sites to generate $\alpha$-glucose and $\alpha$-maltose [5,6]. After seed imbibition, $\alpha$-amylase is synthesized in the aleurone layer and scutellum to break down starch granules. Generally, the 
expression of rice $\alpha$-amylase gene $\alpha$ Amys (also called RAmys) is positively and negatively regulated by gibberellin and sugar, respectively $[7,8]$. After imbibition, GA induces the expression of OsGAMYB (also called MYBGA), which directly binds to the GA response element (GARE) and activates the expression of $\alpha A m y s[9,10]$. Meanwhile, the expression of $\alpha A m y s$ is strongly induced by sugar starvation and repressed by various sugars produced during mobilization of endosperm stores [7,11,12]. These results show the complicated regulatory mechanisms of $\alpha$-amylase.

The GA contents in germinating seeds are determined by GA biosynthesis and metabolism. In brief, GA biosynthesis is catalyzed by the combined actions of ent-copalyl diphosphate synthase (CPS), ent-kaurene synthase (KS), ent-kaurene oxidase (KO), entkaurene acid oxidase (KAO), GA 20-oxidase (GA20ox), and GA 3-oxidase (GA3ox), whereas it is inactivated by GA 2-oxidase (GA2ox) [13,14]. The endogenous bioactive GA contents and seed germination rates are correlated with the expression levels of these enzymerelated genes. In a germination-defactive1 ( $g d 1)$ mutant, the expressions of GA biosynthesisassociated genes OsGA20ox1, OsGA20ox2, and OsGA3ox2 were suppressed, while the expression of the GA inactivation gene OsGA2ox3 was dramatically upregulated, resulting in decreased endogenous $\mathrm{GA}_{4}$ content and the inhibition of seed germination [15]. Meanwhile, the GA content was significantly lower in the germinating seed embryo of an OsGA20ox2 loss-of-function mutant, which resulted in a delayed seed germination [16].

In Arabidopsis and rice, changes in the expression level of miR156 affect seed dormancy $[17,18]$. As a target of miR156, the Ideal Plant Architecture 1 (IPA1), which encodes a transcription factor OsSPL14, a member of the SQUAMOSA PROMOTER BINDING PROTEIN-LIKE (SPL) family in rice, is an important regulator of plant development [19-21]. In ipa1 mutant plants, one nucleotide substitution located in the miR156 recognition site perturbs the miR156-regulated degradation of IPA1 mRNA, leading to an ideal plant architecture with reduced tiller number, increased lodging resistance and panicle branches and, thus, an increase in yield $[19,20]$. In addition, IPA1 was also identified as a vital regulator to participate in biotic stress response [22,23]. Here, with a pair of IPA1/ipa1-NILs developed in our laboratory, we found that IPA1 negatively regulates the processes of seed germination and early seedling growth. To elucidate the mechanism, we examined the amylase activity, GA content, and expression of the related genes in the NILs. Meanwhile, the relationship between IPA1 and two transcriptional repressors (WRKY51 and WRKY71) was investigated, respectively. Our work suggests that the elevated levels of IPA1 expression retards seed germination and early seedling growth through GA and WRKY pathways. These findings provide new insight into understanding the function of IPA1 in seedling development.

\section{Results}

\section{1. ipa1 Retards Seed Germination and Early Seedling Growth of Rice}

To investigate the role of the IPA1 gene in rice seedling development, we developed a pair of IPA1/ipa1-NILs and compared the expression pattern of IPA1 in germinating seeds. We found that IPA1 expression was significantly higher in the ipa1-NIL seeds after $24 \mathrm{~h}$ imbibition compared with the IPA1-NIL seeds (Figure 1A). In a germination experiment, the initiation time of seed sprouting was delayed by approximately $12 \mathrm{~h}$ compared to that of the IPA1-NIL seeds (Figure 1B). Meanwhile, the percentage of germinated ipa1-NIL seeds was significantly decreased from 36 to $96 \mathrm{~h}$ after the initial imbibition (Figure 1B). Additionally, the plateau values of seed germination peaked later for ipa1-NIL, although no significant difference was found in germination percentage after $108 \mathrm{~h}$ (Figure 1B). Moreover, with the dehulled seeds of NILs, we found that the shoot was significantly decreased in the ipa1-NIL seeds at $48 \mathrm{~h}$ after initial imbibition (Figure 1C). Then, the root and shoot lengths were recorded for intact seeds. At $96 \mathrm{~h}$ after germination in Petri dishes, the shoot length was decreased by $22.66 \%$ and the root length was decreased by $24.53 \%$ in the ipa1-NIL seedlings compared with those of the IPA1-NIL seedlings (Figure 1D). Overall, 
these results indicate that IPA1 participates in seed germination and early seedling growth in rice and that ipa1 could retard these processes.

A

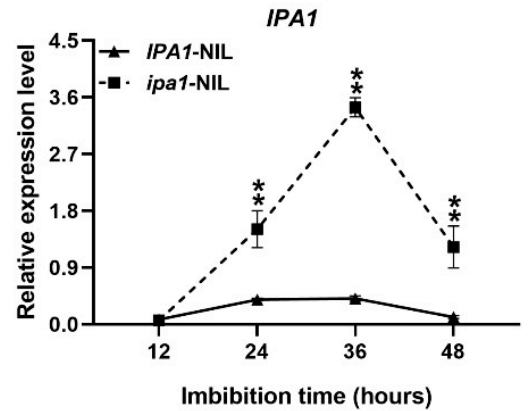

C

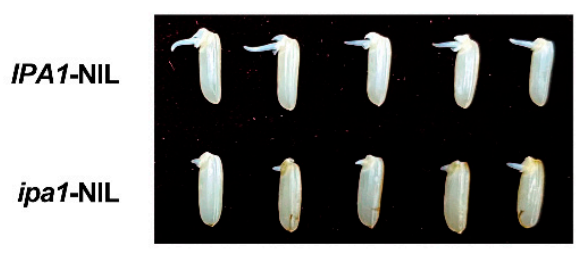

B



D

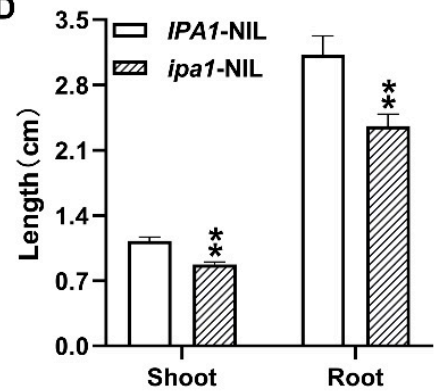

Figure 1. IPA1 participates in seed germination and early seedling growth in rice. (A) The relative expression level of IPA1 in the NILs. (B) Seed germination was comparatively delayed in ipa1-NIL plants. (C) Morphology of dehulled seeds at $48 \mathrm{~h}$ after initial imbibition. (D) The shoots and roots were significantly shorter in ipa1-NIL plants compared with IPA1-NIL plants after $96 \mathrm{~h}$ germinated in the Petri dishes at $30^{\circ} \mathrm{C}$. Values are means $\pm \mathrm{SE}(n=3)$. More than 50 seeds were measured in each replicate. Significant differences were determined using Student's $t$-test $\left({ }^{*} p<0.05,{ }^{* *} p<0.01\right)$.

\subsection{IPA1 Negatively Regulates Starch Metabolism during Seed Germination and Early Seedling Growth}

Sugar is a direct source of energy for seedling vigor. To investigate whether IPA1 regulates seed germination and early seedling growth by modulating sugar accumulation, the sugar content was detected in IPA1/ipa1-NILs. We found that the soluble sugar content of the ipa1-NIL seeds was decreased by $11.63 \%, 19.05 \%$, and $6.80 \%$ after 12,48 , and $96 \mathrm{~h}$ imbibition, in the embryo, respectively (Figure 2A), while no significant difference between the NILs was found in the endosperm except for $96 \mathrm{~h}$ after initial imbibition (Figure 2A). Amylase is a major enzyme involved in the hydrolysis of starch to soluble sugar during seed germination and seedling growth. At 12 and $48 \mathrm{~h}$ of imbibition, the total amylase activity in ipa1-NIL seeds was decreased by $40 \%$ and $23.08 \%$, respectively, with the $\alpha$-amylase activity decreasing by $73.67 \%$ and $16.67 \%$, respectively (Figure $2 B$ ). Then, the transcript levels of genes encoding $\alpha$-amylases were measured. The expression of $R A m y 1 A$ and $R A m y 1 C$ was significantly lower in ipa1-NIL seeds at 12-24 h of imbibition (Figure 2C,D). Meanwhile, at $12 \mathrm{~h}$ of imbibition, $R A m y 3 B / C, R A m y 3 D$, and $R A m y 3 E$ were significantly downregulated in the ipa1-NIL seeds (Figure 2E-G). It has been reported that the $R A m y 3$ subfamily of genes, especially $R A m y 3 D$, are induced by sugar starvation during germination and early seedling growth $[24,25]$. In the present study, the expression of $R A m y 3 D$ was induced quickly in the ipa1-NIL seeds, and the levels of RAmy3D were 2.16-, 2.63-, and 5.21-fold higher compared to that in the IPA1-NIL seeds at 24, 36, and $48 \mathrm{~h}$ after imbibition, respectively (Figure 2F). Similarly, $R A m y 3 B / C$ and $R A m y 3 E$ were also upregulated in the ipa1-NIL seeds at $48 \mathrm{~h}$ after imbibition (Figure 2E,G). Additionally, two sucrose transporter genes OsSUT1 and OsSUT4 were found to be downregulated by $62.72 \%$ and $54.86 \%$ in ipa1-NIL, respectively, at $12 \mathrm{~h}$ of imbibition, and then they were induced to be upregulated (Figure $2 \mathrm{H}, \mathrm{I}$ ), the same as to 
that of $R A m y 3 D$. Taken together, these results suggest that IPA1 negatively regulates starch metabolism during germination and early seedling growth.

A

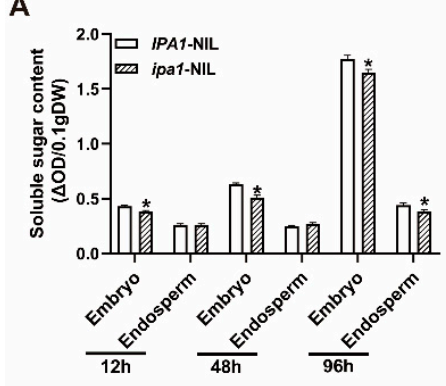

D

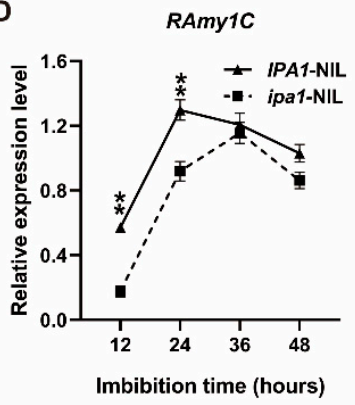

G

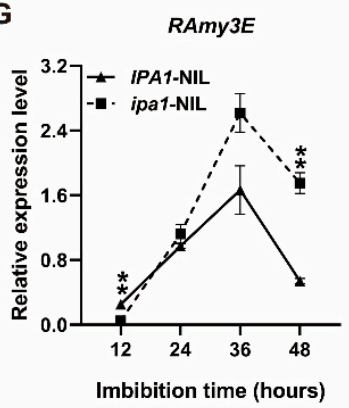

B

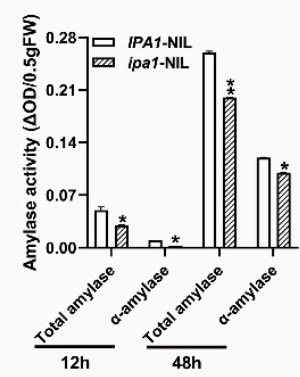

E

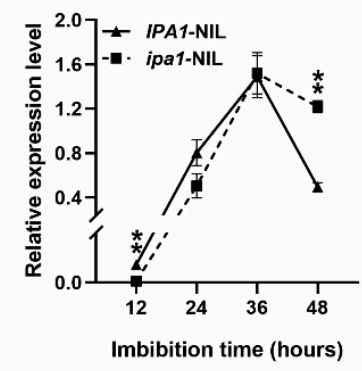

H

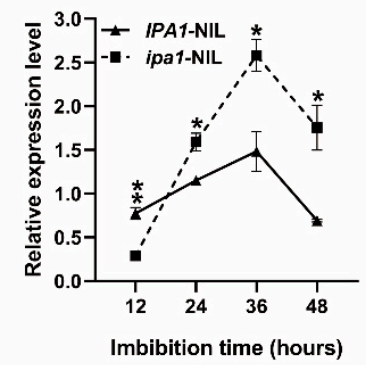

C
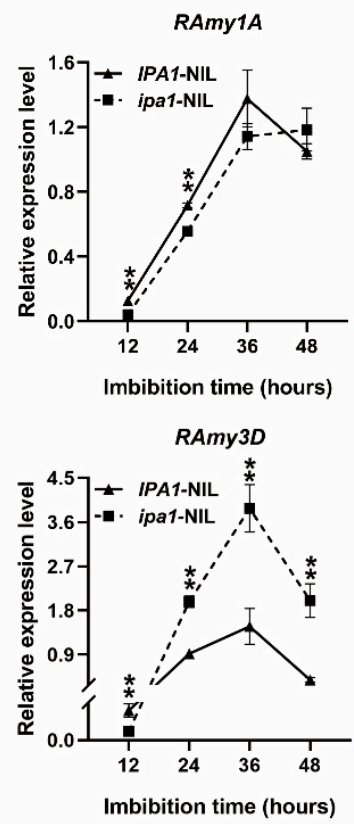

I

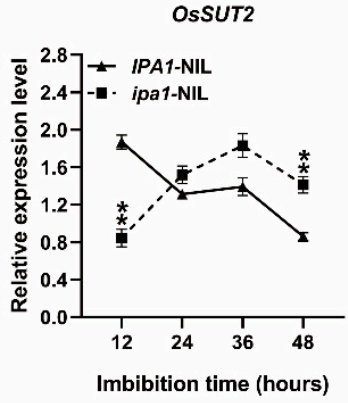

Figure 2. The impacts of IPA1 on starch metabolism during germination and early seedling growth. (A) The soluble sugar content of NILs in the embryo and endosperm at different time points. (B) The amylase activity in NILs. (C-G) The relative expression level of $\alpha$-amylase genes $R A m y 1 A(\mathbf{C}), R A m y 1 C$ (D), $R A m y 3 B / C(\mathbf{E}), R A m y 3 D(\mathbf{F})$, and $R A m y 3 E(\mathbf{G})$. $(\mathbf{H}, \mathbf{I})$ The relative expression level of sugar transport-related genes OsSUT1 (H) and OsSUT2 (I). Significant differences were determined using Student's $t$-test $\left({ }^{*} p<0.05,{ }^{* *} p<0.01\right)$.

\subsection{The Retarding Effect of Seed Germination and Early Seeding Growth in the ipa1-NIL Seeds Caused by GA Defect}

In germinating grains, bioactive GAs are synthesized in the embryo and transported to the aleurone layer to trigger $\alpha A m y s$ expression [26]. In our study, the total contents of the bioactive GAs were markedly decreased in the ipa1-NIL seeds at $48 \mathrm{~h}$ of imbibition (Figure $3 \mathrm{~A}$ ). Among them, the contents of $\mathrm{GA}_{3}, \mathrm{GA}_{4}$, and $\mathrm{GA}_{7}$ were decreased by $22.86 \%$, $11.90 \%$, and $56.18 \%$, respectively (Figure $3 \mathrm{~A}$ ). It has been reported that GAs could induce the

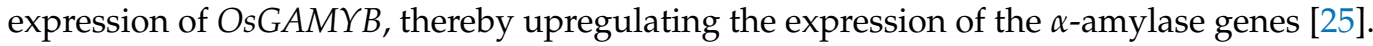
In the present study, the expression of OsGAMYB was downregulated significantly in ipa1NIL seeds during germination (Figure $3 \mathrm{~B}$ ). Meanwhile, when exogenous $\mathrm{GA}_{3}$ was applied, the germination rate of the ipa1-NIL seeds was markedly accelerated (Figure 3C-E), and the shoot and root lengths of the ipa1-NIL seeds were significantly increased after $96 \mathrm{~h}$ germinated on filter paper soaked with $\mathrm{GA}_{3}$ solution (Figure $3 \mathrm{~F}, \mathrm{G}$ ). These data suggest that ipa1 retards the seed germination and early seedling growth at least via a mechanism mediated by a reduction in the abundance of bioactive GAs. 
A



D

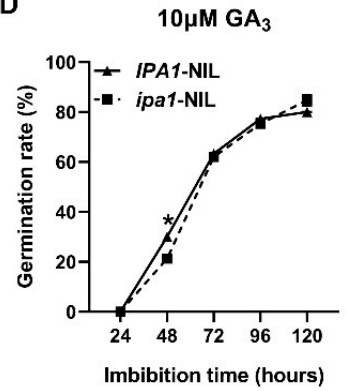

E
B
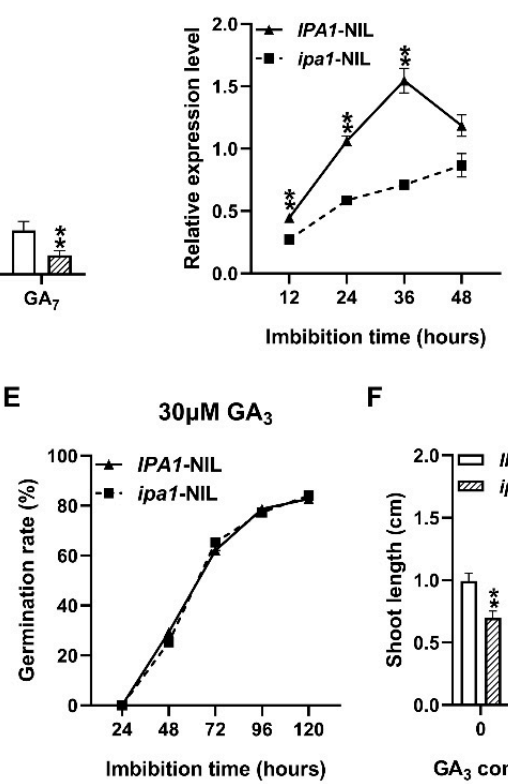

$\mathbf{F}$

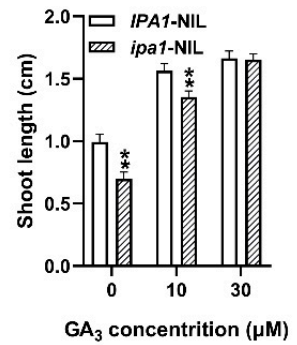

C

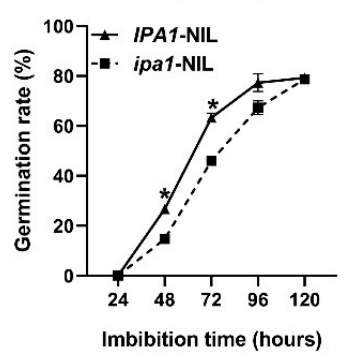

G

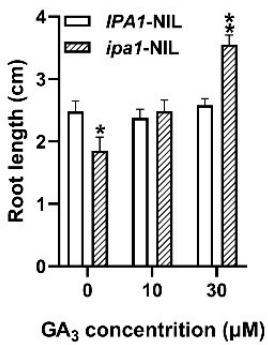

Figure 3. Retarded seed germination and early seedling growth in ipa1-NIL seeds is caused by GA defects. (A) The contents of bioactive GAs in the seeds after $48 \mathrm{~h}$ imbibition. Values are means $\pm \mathrm{SE}(n=3)$. (B) The relative expression level of OsGAMYB at different time points. Values are means \pm SE $(n=3)$. (C-E) Germination rate of NILs soaked in $0 \mu \mathrm{M}(\mathbf{C})$, $10 \mu \mathrm{M}(\mathbf{D})$, and $30 \mu \mathrm{M}(\mathbf{E}) \mathrm{GA}_{3}$ solution. Values are means $\pm \mathrm{SE}(n=3)$. More than 50 seeds were measured in each replicate. $(\mathbf{F}, \mathbf{G})$ The shoot $(\mathbf{F})$ and root $(\mathrm{G})$ lengths of seedlings grow on filter paper soaked with water or $\mathrm{GA}_{3}$ solution. Values are means \pm SE $(n=36)$. Significant differences were determined using Student's $t$-test $\left({ }^{*} p<0.05,{ }^{* *} p<0.01\right)$.

\subsection{Enhanced GA Deactivation in the ipa1-NIL}

Bioactive gibberellins are regulated by changes in biosynthetic and deactivation processes. To investigate how the bioactive GAs were decreased in the ipa1-NIL seeds, the expression of GA biosynthetic and inactivated genes was analyzed in the NILs (Figure 4). OsGA20ox1, a representative gene in the third step of GA biosynthesis, was significantly downregulated in the ipa1-NIL during 12-36 h of seed imbibition (Figure 4C), although no significant difference was observed in the expression levels of the GA synthesis-related genes OsCPS1, OsKAO and OsGA20ox2 between the NILs except for OsKAO at the point of $36 \mathrm{~h}$ (Figure $4 \mathrm{~A}, \mathrm{~B}, \mathrm{D}$ ). The GA2ox enzymes are involved in GA deactivation in rice. In this study, the OsGA2ox3, OsGA2ox6, and OsGA20x8 were upregulated in ipa1-NIL during almost the entire imbibition period (Figure 4E,G), and OsGA2ox9 also showed a higher expression level in ipa1-NIL after $36 \mathrm{~h}$, although it was downregulated in the beginning (Figure $4 \mathrm{H}$ ). Overall, elevated expression of IPA1 enhanced the deactivation process of GAs during seed germination and early seedling growth. 
A



E

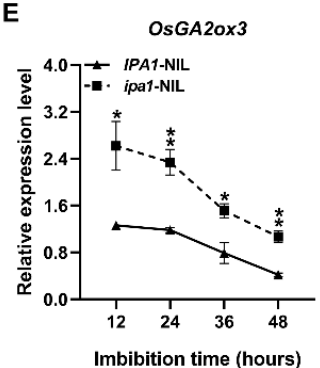

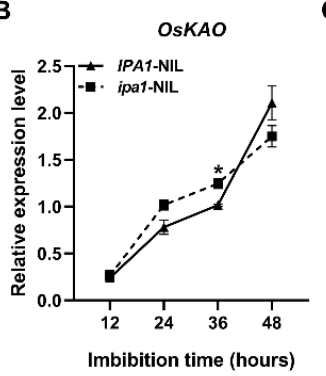

$\mathbf{F}$



C

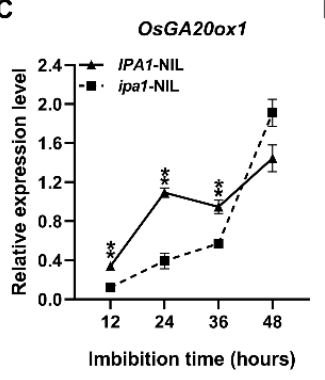

G

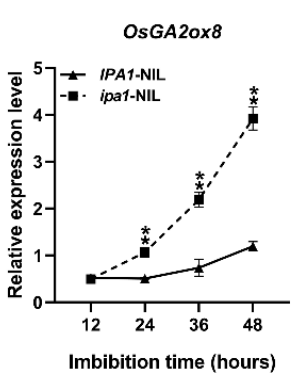

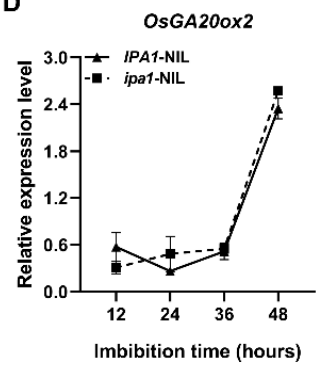

H

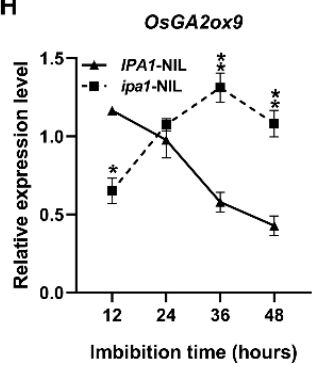

Figure 4. The transcript levels of genes related to GA biosynthesis and inactivation at different time points. (A-D) The relative expression level of GA biosynthesis-related gene OsCPS1 (A), OsKAO (B), OsGA20ox1 (C), and OsGA20ox2 (D). (E-H) The relative expression level of GA metabolism-related gene OsGA2ox3 (E), OsGA2ox6 (F), OsGA2ox8 (G), and OsGA2ox9 $(\mathbf{H})$. Values are means \pm SE $(n=3)$. Significant differences were determined using Student's $t$-test $\left({ }^{*} p<0.05\right.$, ** $p<0.01)$.

\subsection{IPA1 Directly Binds to OsWRKY51 and OsWRKY71 and Promotes Their Expression}

Previous studies have demonstrated that OsWRKY51 and OsWRKY71 could suppress the GA-induced expression of $\alpha$-amylase genes by interfering with the transactivator OsGAMYB [27], and IPA1 was found to be enriched in the OsWRKY51 promoter [28]. In this study, we found that the expression levels of OsWRKY51 and OsWRKY71 in ipa1-NIL seeds were significantly upregulated after $24 \mathrm{~h}$ imbibition (Figure 5A,B). By transient dualluciferase (LUC) assays with rice protoplasts, we found that IPA1 promoted expression of the luciferase reporter gene driven by the OsWRKY51 and OsWRKY71 promoter, respectively (Figure 5C,D). As a transcription factor, IPA1 could regulate the expression of its target genes by binding to the core motif GTAC and/or TGGGCC/T in promoters [28]. Then, we conducted sequence analyses and identified four and eight GTAC motifs in the OsWRKY51 and OsWRKY71 promoter, respectively (Figure 5E,F). Yeast one-hybrid (Y1H) assays were performed to evaluate if IPA1 directly binds to the promoters of OsWRKY51 and OsWRKY71. The cells co-transformed with bait and the prey vectors could grew well on SD/ - Leu / - Ura / AbAi plates (Figure 5E,F), indicating that IPA1 can directly bind to the promoters of OsWRKY51 and OsWRKY71. Taking these results together, we conclude that OsWRKY51 and OsWRKY71 are the direct target genes of IPA1. 
A

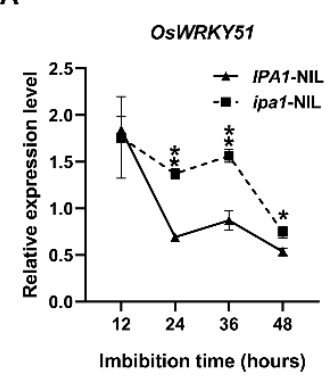

B



E

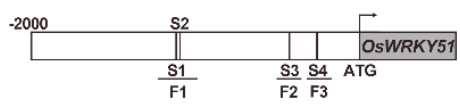

$\mathrm{SD} /$-Leu/-Ura/AbA



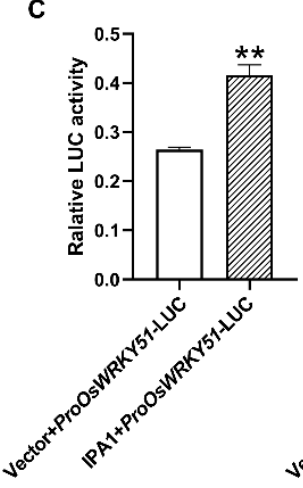



Figure 5. IPA1 positively regulates the expression of OsWRKY51 and OsWRKY71. (A,B) The relative expression level of OsWRKY51 (A) and OsWRKY71 (B) at different time points. Values are means \pm SE $(n=3)$. (C,D) Relative LUC activities of ProOsWRKY51 (C) and ProOsWRKY71 (D) reporter after co-expression with IPA1 in rice protoplasts, respectively. The pRGV vector was used as control. Relative LUC activity was calculated by LUC/Ren. Values are means \pm SD $(n=3)$. Significant differences were determined using Student's $t$-test $\left({ }^{*} p<0.05,{ }^{* *} p<0.01\right)$. (E,F) Y1H assays to dissect the binding regions of IPA1 in the promoter regions of OsWRKY51 (E) and OsWRKY71 (F), respectively. The core GTAC motifs are marked as S1, S2, and so on.

\section{Discussion}

IPA1/OsSPL14 is a pleiotropic gene that plays an intricate role in rice plant development and stress response $[19,23,29]$. In ipa1 plants, a point mutation in the miR156 recognition site perturbed the miR156-regulated degradation of IPA1 mRNA, leading to changed plant architecture [19]. Previous studies have reported that the overexpression of IPA1 or knockout of miR156 enhances seed dormancy [18,22]. Here, we found that the expression level of IPA1 was rapidly upregulated in the soaked ipa1-NIL seeds (Figure 1A). Based on the seed germination rate as well as shoot and root lengths of NILs (Figure 1B-D), our study suggested that the higher expression level of IPA1 in ipa1-NIL delayed seed germination and retarded early seedling growth.

Seed germination and embryo growth rely on the energy supplied by starch decomposition. In the endosperm, starch is decomposed into soluble sugars that are transported into the germinating embryo axis [11,30]. In addition, the enzyme $\alpha$-amylase is responsible for the degradation of reserve carbohydrate to soluble sugars [31]. In the embryo, soluble sugars provide substrates and energy for fueling embryonic development. In the present study, a lower soluble sugar content was found in the ipa1-NIL embryo (Figure 2A). Further analyses found that the activity of $\alpha$-amylase was significantly decreased in ipa1-NIL seeds (Figure 2B). Therefore, the delayed germination and retarded early seedling growth in ipa1-NIL seeds could be caused by the suppression of starch metabolism.

It has been reported that GA plays a critical role in promoting seed germination [1]. In plants, $\mathrm{GA}_{1}, \mathrm{GA}_{3}, \mathrm{GA}_{4}$, and $\mathrm{GA}_{7}$ are the major bioactive $\mathrm{GA}$ forms [13]. Our results revealed that the contents of $\mathrm{GA}_{3}, \mathrm{GA}_{4}$, and $\mathrm{GA}_{7}$ were dramatically decreased in ipa1-NIL compared with those in the IPA1-NIL seeds (Figure 3A). These findings are consistent 
with a previous study which showed that the content of $\mathrm{GA}_{3}$ and $\mathrm{GA}_{7}$ was decreased in the fresh seeds of the miR156 mutant [18]. Therefore, we further investigated the effect of exogenous GA on the seed germination of the NILs and, as a result, GA -promoted germination and seedling growth were clearly observed in ipa1-NIL seeds (Figure 3C-G), although previous studies have reported that the exogenous GA application has little effect on the germination of the miR156 mutant or IPA1-OE seeds [18,22]. Altogether, these results support the hypothesis that the elevated expression of IPA1 delays seed germination and retards early seedling growth mainly through the GA pathway.

The contents of bioactive GAs were cooperatively regulated by biosynthesis and inactivation. In rice, OsGA20ox and OsGA2ox are involved in GA biosynthesis and inactive during seed germination, respectively $[15,32]$. To explore the mechanisms of how ipa1 downregulates the content of GAs, the expression levels of GA synthesis- and inactivation-related genes were investigated. For the GA synthesis-related genes, our results demonstrated that OsGA20ox1 was markedly downregulated in the ipa1-NIL seeds during germination (Figure 4C). Although the ChIP-qPCR and EMSA assays demonstrated that IPA1 could directly bind to the GTAC-containing regions in the promoters of the two GA synthesisrelated genes OsCPS1 and OsKAO [18], no obvious difference was found in the expression of OsCPS1 and OsKAO between the NILs (Figure 4A,B). For the GA inactivation-related genes, OsGA2ox3, OsGA2ox6, OsGA2ox8, and OsGA2ox9 were generally upregulated in ipa1-NIL. Therefore, the lower expression level of the GA synthesis-related gene OsGA20ox1 and the higher level of the GA inactivation-related genes could lead to the lower contents of GAs in ipa1-NILs seeds.

The $O S G A M Y B$ gene is a GA-regulated transcription factor required for the transcriptional activation of $\alpha$-amylase genes [7,33]. In the ipa1-NIL seeds, the expression level of OsGAMYB was significantly lower (Figure 3B). Meanwhile, RAmy $1 A$ and RAmy $1 C$ were significantly downregulated during the early stage of germination and $R A m y 3 B / C$, $R A m y 3 D$, and $R A m y 3 E$ were also downregulated in the beginning. Interestingly, $R A m y 3 B / C$, $R A m y 3 D$, and $R A m y 3 E$, especially $R A m y 3 D$, were then upregulated quickly, which might be induced by sugar starvation as reported in the previous studies [24,25]. These observations suggested that IPA1 negatively regulates the early seedling development of rice by interfering with starch metabolism via the GA pathway.

The GA response in the aleurone cells is influenced by various factors. In recent decades, many members of the WRKY family have been reported to participate in GAmediated seed germination. In rice, OsWRKY 24 can bind to the $A m y 32 b$ promoter and independently suppress GA induction of the Amy32b expression [34]. Recently, OsWRKY72 was identified as a negative regulator in rice germination to suppress GA accumulation through the "LRK1-OsKO2" pathway in the aleurone layer [35]. OsWRKY51 and OsWRKY71 function as heterologous dimers and directly interfere with GA-induced transcription factor OsGAMYB to inhibit the expression of $\alpha$ Amys $[27,36]$. Although OsWRKY51 does not bind to the $A m y 32 b$ promoter in vitro, it could interact with OsWRKY71 to enhance the binding affinity of OsWRKY71 to the W-box [27]. In the present study, we found that the transcript levels of OsWRKY51 and OsWRKY71 were significantly upregulated in ipa1-NIL seeds (Figure 5A,B). As a transcription factor, IPA1 could regulate the expression of its target genes by binding to the core motif GTAC and/or TGGGCC/T in promoters [28]. Based on the results of the $\mathrm{Y} 1 \mathrm{H}$ and transient dual-luciferase assays, our results suggested that IPA1 can directly activate the expression of OsWRKY51 and OsWRKY71 (Figure 5E,F), which further influences the binding affinity of OsGAMYB to the promoter of $\alpha$ Amys, thus downregulating its expression.

Recently, the expanding knowledge on IPA1 has led to the proposal of IPA1 as a pleiotropic gene to improve agronomic traits in rice [22,23]. Seed germination and early seedling development are the traits we were concerned with here. Generally, when the seeds are soaked in water, their GA level increases dramatically so as to promote seed germination [26]. In our study, the expression of IPA1 was upregulated quickly in the germinating seeds of the ipa1-NIL. Meanwhile, the GA synthesis-related gene OsGA20ox1 
and the GA inactivation-related genes such as OsGA2ox3, OsGA2ox6, OsGA2ox8, and OsGA20x9 were detected to be downregulated and upregulated, respectively. As a result, the GA level was decreased and then the expression of OsGAMYB was downregulated in ipa1-NIL. Additionally, IPA1 could promote the expression of OsWRKY51 and OsWRKY71 directly, which would influence the binding affinity of OsGAMYB to the $\alpha$-amylase genes. Therefore, our results suggested that IPA1 retards seed germination and early seedling growth by interfering with starch metabolism via both the GA and WRKY pathways.

\section{Materials and Methods}

\subsection{Plant Materials}

To generate near-isogenic lines (NILs) of ipa1 and IPA1, the ipa1-containing japonica line Shaoniejing (SNJ) [19] was crossed with an indica cultivar Yuetai B (IPA1/IPA1) to develop the Yuetai $B / S N J F_{1}$ plants. Then, the $F_{1}$ plants were backcrossed with Yuetai $B$ to develop the $\mathrm{BC}_{1} \mathrm{~F}_{1}$ plants. Subsequently, one of the $\mathrm{BC}_{1} \mathrm{~F}_{1}$ plants was self-crossed for six generations to develop Yuetai $\mathrm{B} / \mathrm{SNJ} \mathrm{BC}_{1} \mathrm{~F}_{7}$ plants. Using marker-assisted selection, a $\mathrm{BC}_{1} \mathrm{~F}_{7}$ plant with the genotype IPA1 / ipa1 on the IPA1 locus was obtained. In the self-crossed progeny of this $\mathrm{BC}_{1} \mathrm{~F}_{7}$ plant, the plants with the genotype IPA1/IPA1 were identified as IPA1-NIL, whereas the plants with the genotype ipa1/ipa1 were identified as ipa1-NIL.

\subsection{Seed Germination Analysis}

Sterilized NIL seeds were incubated at $30{ }^{\circ} \mathrm{C}$ in the dark with water, $10 \mu \mathrm{M} \mathrm{GA}_{3}$, or $30 \mu \mathrm{M} \mathrm{GA}$. Three replicates (more than 50 seeds/replicate) were analyzed for each treatment. The seed germination rate was calculated at different time points after imbibition. A seed was considered to have germinated when the radicle or shoot length was longer than $1 \mathrm{~mm}$.

\subsection{Determination of $\alpha$-Amylase Activity}

The amylase activity was quantitatively determined by a modified version of the 3,5dinitrosalicylic acid method, as described in previous studies [37,38]. Briefly, the seeds were incubated in the water at $28^{\circ} \mathrm{C}$. After 12 and $48 \mathrm{~h}$ incubation, the seeds were collected and ground in liquid nitrogen. Powder $(0.5 \mathrm{~g})$ was used for enzyme extraction. To determine the $\alpha$-amylase activity, $1 \mathrm{~mL}$ crude enzyme extract was incubated in the water at $70{ }^{\circ} \mathrm{C}$ for $15 \mathrm{~min}$ to inhibit the activity of $\beta$-amylase. The additional $1 \mathrm{~mL}$ enzyme extract was not heated and used to measure the total amylase activity. Then, each enzyme extract was mixed with $1 \mathrm{~mL}$ of $1 \%(w / v)$ soluble starch dissolved in citric acid buffer $(\mathrm{pH}=5.6)$. After heating in a water bath at $40^{\circ} \mathrm{C}$ for $5 \mathrm{~min}, 2 \mathrm{~mL}$ 3,5-dinitrosalicylic acid reagent was added, and the mixture was boiled for $5 \mathrm{~min}$. The absorbance of the mixture was measured at wavelengths of $540 \mathrm{~nm}$. Three replicates were analyzed for each treatment.

\subsection{Measurement of Soluble Sugar Content}

The soluble sugar content was quantified by the anthrone method [39] with minor modifications. The embryos and endosperms of germinating seeds were collected from each replicate at 12,48 , and $96 \mathrm{~h}$ and immediately dried to a constant weight at $70{ }^{\circ} \mathrm{C}$. Subsequently, the sample was ground, and $0.01 \mathrm{~g}$ powder was mixed with $800 \mu \mathrm{L}$ of $80 \%$ $(v / v)$ ethanol. The mixture was heated at $80{ }^{\circ} \mathrm{C}$ for $30 \mathrm{~min}$, cooled, centrifuged at $3000 \mathrm{rpm}$ $(664 \times g)$ for $10 \mathrm{~min}$, and diluted to a volume of $2 \mathrm{~mL}$ with $80 \%(v / v)$ ethanol. The reaction mix contained $200 \mu \mathrm{L}$ extract and $1 \mathrm{~mL}$ reagent was heated at $95^{\circ} \mathrm{C}$ for $15 \mathrm{~min}$. The absorbance of samples was finally recorded at $620 \mathrm{~nm}$. The soluble content was calculated using glucose as the standard. Three replicates were analyzed for each treatment.

\subsection{Measurement of Endogenous Bioactive GA Content}

The endogenous GA contents in seeds were determined as described in [40]. In brief, the dehulled seeds were ground in liquid nitrogen, and $120 \mathrm{mg}$ powder was mixed with $1.2 \mathrm{~mL} 80 \%(v / v)$ methanol at $4{ }^{\circ} \mathrm{C}$. After centrifugation at $12,000 \times g$ for $15 \mathrm{~min}$ at $4{ }^{\circ} \mathrm{C}$, the 
supernatant was dried under a stream of $\mathrm{N}_{2}$. Then, the residues were dissolved in $30 \%$ methanol and centrifuged. The supernatant was collected for LC-MS analysis.

\subsection{RNA Extraction and $q P C R$}

After 12, 24, 36, and $48 \mathrm{~h}$ incubation, total RNA from the germinating seeds was extracted with TRIzol reagent (Invitrogen, Carlsbad, CA, USA). First-strand cDNA was synthesized from $2 \mu \mathrm{g}$ RNA in a total of $20 \mu \mathrm{L}$ reaction system with an ABScript III RT Master Mix with gDNA Remover (ABclonal, Wuhan, China) according to the manufacturer's instructions. Synthesized cDNAs were used for qPCR with $2 \times$ Universal SYBR Green Fast qPCR Mix (ABclonal, Wuhan, China) on a CFX384 ${ }^{\mathrm{TM}}$ real-time PCR Detection System (Bio-Rad, Hercules, CA, USA). The primers used for qPCR are listed in Table S1. PCR thermal cycling conditions were as follows: initial denaturation, $95^{\circ} \mathrm{C}$ for $5 \mathrm{~min} ; 40$ cycles of denaturation $95^{\circ} \mathrm{C}$ for $10 \mathrm{sec}$, annealing and extension at $60^{\circ} \mathrm{C}$ for $30 \mathrm{~s}$; followed by melting and plate reading. Three biological replicates were included for each sample. The OsActin gene expression was used as an internal control to normalize the expression of target genes.

\subsection{Dual-Luciferase Assay}

The dual-luciferase assays were performed according to a previously described method [29]. The promoter of OsWRKY51 and OsWRKY71 was amplified from the genomic DNA (primer pairs listed in Table S1) and cloned into the upstream of the LUC reporter gene to generate the ProOsWRKY51-LUC and ProOsWRKY71-LUC reporter construct, respectively. The luciferase gene from Renilla reniformis (Ren) under control of the CaMV $35 \mathrm{~S}$ promoter was used as an internal control. The cDNA of IPA1 was amplified (primer pairs listed in Table S1) and inserted into the HindIII/BamHI digested pRGV vector [41] to generate the Ubi:IPA1 effector construct. The combined reporter and effector plasmids were co-transformed into rice protoplasts as described in [42]. An empty pRGV vector co-transformed with the reporter construct was used as a vector control. The LUC activity was measured with the Dual-Luciferase Assay Kit (Promega, Beijing, China) according to the manufacturer's recommendations, and the relative LUC activity was calculated as the ratio of LUC/Ren.

\subsection{Yeast One-Hybrid Assay}

The coding region of IPA1-SBP was amplified by PCR and cloned into a pGADT7 vector to produce an IPA1 $1_{\mathrm{SBP}}-\mathrm{AD}$ construct. Various truncated fragments of the promoter regions of OsWRKY51 and OsWRKY71 were amplified and ligated into the pABAi vector to generate the bait vectors. After linearization by the BstBI enzyme, the bait vector co-transformed with the prey vector into the yeast strain Y1HGold. The transformants were grown on $\mathrm{SD} /-\mathrm{Ura} /-$ Leu plates at $30{ }^{\circ} \mathrm{C}$ for 3 days, then grown on $\mathrm{SD} /-\mathrm{Ura} /-$ Leu/AbAi plates. Yeast strains containing the empty pGADT7 in combination with the bait vector were used as the negative control.

Supplementary Materials: Supplementary materials can be found at https://www.mdpi.com/ article/10.3390/ijms22126605/s1.

Author Contributions: Conceptualization, Y.H. and Z.Z.; methodology, Y.H. and M.Z.; investigation, Y.H., M.Z., Z.L., S.J., Z.H. (Zijun He), and S.X.; writing-original draft preparation, Y.H.; writingreview and editing, Z.H. (Zijun He), X.C., Z.H. (Zhongli Hu), and Z.Z.; funding acquisition, Y.H. and Z.Z. All authors have read and agreed to the published version of the manuscript.

Funding: This research was funded by the National Natural Science Foundation of China (no. 31901522), the Special Transgenic Program of Chinese Ministry of Agriculture (no. 2016ZX08001004002), and the Hubei Collaborative Innovation Center of Hybrid Rice.

Institutional Review Board Statement: Not applicable.

Informed Consent Statement: Not applicable. 
Data Availability Statement: Data are available on request to the corresponding author.

Acknowledgments: The authors thank Qian Qian from the China National Rice Research Institute for providing the ipa1 donor rice cv. Shaoniejing.

Conflicts of Interest: The authors declare no conflict of interest.

\section{References}

1. Rajjou, L.; Duval, M.; Gallardo, K.; Catusse, J.; Bally, J.; Job, C.; Job, D. Seed germination and vigor. Annu. Rev. Plant Biol. 2012, 63, 507-533. [CrossRef]

2. Bewley, J.D. Seed germination and dormancy. Plant Cell 1997, 9, 1055-1066. [CrossRef] [PubMed]

3. Matsukura, C.; Saitoh, T.; Hirose, T.; Ohsugi, R.; Perata, P.; Yamaguchi, J. Sugar uptake and transport in rice embryo. Expression of companion cell-specific sucrose transporter (OsSUT1) induced by sugar and light. Plant Physiol. 2000, 124, 85-93. [CrossRef] [PubMed]

4. Damaris, R.N.; Lin, Z.; Yang, P.; He, D. The rice alpha-amylase, conserved regulator of seed maturation and germination. Int. J. Mol. Sci. 2019, 20, 450. [CrossRef] [PubMed]

5. Pujadas, G.; Palau, J. Evolution of alpha-amylases: Architectural features and key residues in the stabilization of the $(\beta / \alpha)_{8}$ scaffold. Mol. Biol. Evol. 2001, 18, 38-54. [CrossRef] [PubMed]

6. Yu, S.-M.; Lo, S.-F.; Ho, T.-H.D. Source-sink communication: Regulated by hormone, nutrient, and stress cross-signaling. Trends Plant Sci. 2015, 20, 844-857. [CrossRef]

7. Chen, P.-W.; Chiang, C.-M.; Tseng, T.-H.; Yu, S.-M. Interaction between rice MYBGA and the gibberellin response element controls tissue-specific sugar sensitivity of $\alpha$-Amylase genes. Plant Cell 2006, 18, 2326-2340. [CrossRef]

8. Shu, K.; Liu, X.-D.; Xie, Q.; He, Z.-H. Two faces of one seed: Hormonal regulation of dormancy and germination. Mol. Plant 2016, 9, 34-45. [CrossRef]

9. Hong, Y.-F.; Ho, T.-H.; Wu, C.-F.; Ho, S.-L.; Yeh, R.-H.; Lu, C.-A.; Chen, P.-W.; Yu, L.-C.; Chao, A.; Yu, S.-M. Convergent starvation signals and hormone crosstalk in regulating nutrient mobilization upon germination in cereals. Plant Cell 2012, 24, $2857-2873$. [CrossRef] [PubMed]

10. Kaneko, M.; Inukai, Y.; Ueguchi-Tanaka, M.; Itoh, H.; Izawa, T.; Kobayashi, Y.; Hattori, T.; Miyao, A.; Hirochika, H.; Ashikari, M.; et al. Loss-of-function mutations of the rice GAMYB gene impair alpha-amylase expression in aleurone and flower development. Plant Cell 2004, 16, 33-44. [CrossRef]

11. Thomas, B.R.; Rodriguez, R.L. Metabolite signals regulate gene expression and source/sink relations in cereal seedlings. Plant Physiol. 1994, 106, 1235-1239. [CrossRef] [PubMed]

12. Rolland, F.; Baena-Gonzalez, E.; Sheen, J. Sugar sensing and signaling in plants: Conserved and novel mechanisms. Ann. Rev. Plant Biol. 2006, 57, 675-709. [CrossRef] [PubMed]

13. Yamaguchi, S. Gibberellin metabolism and its regulation. Annu. Rev. Plant Biol. 2008, 59, 225-251. [CrossRef]

14. Vishal, B.; Kumar, P.P. Regulation of seed germination and abiotic stresses by gibberellins and abscisic acid. Front. Plant Sci. 2018, 9, 838. [CrossRef]

15. Guo, X.-L.; Hou, X.-M.; Fang, J.; Wei, P.-W.; Xu, B.; Chen, M.-L.; Feng, Y.-Q.; Chu, C.-C. The rice GERMINATION DEFECTIVE 1, encoding a B3 domain transcriptional repressor, regulates seed germination and seedling development by integrating GA and carbohydrate metabolism. Plant J. 2013, 75, 403-416. [CrossRef]

16. Ye, H.; Feng, J.-H.; Zhang, L.-H.; Zhang, J.-F.; Mispan, M.S.; Cao, Z.-Q.; Beighley, D.H.; Yang, J.-C.; Gu, X.-Y. Map-based cloning of seed dormancy1-2 identified a gibberellin synthesis gene regulating the development of endosperm-imposed dormancy in rice. Plant Physiol. 2015, 169, 2152-2165. [PubMed]

17. Huo, H.-Q.; Wei, S.-H.; Bradford, K.J. DELAY OF GERMINATION1 (DOG1) regulates both seed dormancy and flowering time through microRNA pathways. Proc. Natl. Acad. Sci. USA 2016, 113, E2199-E2206. [CrossRef] [PubMed]

18. Miao, C.-B.; Wang, Z.; Zhang, L.; Yao, J.-J.; Hua, K.; Liu, X.; Shi, H.-Z.; Zhu, J.-K. The grain yield modulator miR156 regulates seed dormancy through the gibberellin pathway in rice. Nat. Commun. 2019, 10, 3822. [CrossRef] [PubMed]

19. Jiao, Y.-Q.; Wang, Y.-H.; Xue, D.-W.; Wang, J.; Yan, M.-X.; Liu, G.-F.; Dong, G.-J.; Zeng, D.-L.; Lu, Z.-F.; Zhu, X.-D.; et al. Regulation of OsSPL14 by OsmiR156 defines ideal plant architecture in rice. Nat. Genet. 2010, 42, 541-544. [CrossRef]

20. Miura, K.; Ikeda, M.; Matsubara, A.; Song, X.-J.; Ito, M.; Asano, K.; Matsuoka, M.; Kitano, H.; Ashikari, M. OsSPL14 promotes panicle branching and higher grain productivity in rice. Nat. Genet. 2010, 42, 545-549. [CrossRef] [PubMed]

21. Wang, F.; Han, T.-W.; Song, Q.-X.; Ye, W.-X.; Song, X.-G.; Chu, J.-F.; Li, J.-Y.; Chen, Z.J. Rice circadian clock regulates tiller growth and panicle development through strigolactone signaling and sugar sensing. Plant Cell 2020, 32, 3124-3138. [CrossRef]

22. Liu, M.-M.; Shi, Z.-Y.; Zhang, X.-H.; Wang, M.-X.; Zhang, L.; Zheng, K.-Z.; Liu, J.-Y.; Hu, X.-M.; Di, C.-R.; Qian, Q.; et al. Inducible overexpression of Ideal Plant Architecture1 improves both yield and disease resistance in rice. Nat. Plants 2019, 5, 389-400. [CrossRef] [PubMed]

23. Wang, J.; Zhou, L.; Shi, H.; Chern, M.; Yu, H.; Yi, H.; He, M.; Yin, J.-J.; Zhu, X.-B.; Li, Y.; et al. A single transcription factor promotes both yield and immunity in rice. Science 2018, 361, 1026-1028. [CrossRef]

24. Hwang, Y.S.; Thomas, B.R.; Rodriguez, R.L. Differential expression of rice $\alpha$-amylase genes during seedling development under anoxia. Plant Mol. Biol. 1999, 40, 911-920. [CrossRef] [PubMed] 
25. Ma, M.; Cen, W.; Li, R.-B.; Wang, S.-K.; Luo, J.-J. The molecular regulatory pathways and metabolic adaptation in the seed germination and early seedling growth of rice in response to low $\mathrm{O}_{2}$ stress. Plants 2020, 9, 1363. [CrossRef]

26. Kaneko, M.; Itoh, H.; Ueguchi-Tanaka, M.; Ashikari, M.; Matsuoka, M. The $\alpha$-amylase induction in endosperm during rice seed germination is caused by gibberellin synthesized in epithelium. Plant Physiol. 2002, 128, 1264-1270. [CrossRef]

27. Xie, Z.; Zhang, Z.-L.; Zou, X.-L.; Yang, G.-X.; Komatsu, S.; Shen, Q.J. Interactions of two abscisic-acid induced WRKY genes in repressing gibberellin signaling in aleurone cells. Plant J. 2006, 46, 231-242. [CrossRef] [PubMed]

28. Lu, Z.-F.; Yu, H.; Xiong, G.-S.; Wang, J.; Jiao, Y.-Q.; Liu, G.-F.; Jing, Y.-H.; Meng, X.-B.; Hu, X.-M.; Qian, Q.; et al. Genome-wide binding analysis of the transcription activator IDEAL PLANT ARCHITECTURE1 reveals a complex network regulating rice plant architecture. Plant Cell 2013, 25, 3743-3759. [CrossRef] [PubMed]

29. Duan, E.-C.; Wang, Y.-H.; Li, X.-H.; Lin, Q.-B.; Zhang, T.; Wang, Y.-P.; Zhou, C.-L.; Zhang, H.; Jiang, L.; Wang, J.-L.; et al. OsSHI1 regulates plant architecture through modulating the transcriptional activity of IPA1 in rice. Plant Cell 2019, 31, 1026-1042. [CrossRef] [PubMed]

30. Han, C.; Yang, P.-F. Studies on the molecular mechanisms of seed germination. Proteomics 2015, 15, 1671-1679. [CrossRef]

31. Mishra, P.; Dubey, R.S. Effect of aluminium on metabolism of starch and sugars in growing rice seedlings. Acta Physiol. Plant 2007, 30, 265-275. [CrossRef]

32. Lo, S.-F.; Yang, S.-Y.; Chen, K.-T.; Hsing, Y.-I.; Zeevaart, J.A.D.; Chen, L.-J.; Yu, S.-M. A novel class of Gibberellin 2-Oxidases control semidwarfism, tillering, and root development in rice. Plant Cell 2008, 20, 2603-2618. [CrossRef]

33. Gubler, F.; Kalla, R.; Roberts, J.K.; Jacobsen, J.V. Gibberellin-regulated expression of a myb gene in barley aleurone cells: Evidence for Myb transactivation of a high-pI $\alpha$-amylase gene promoter. Plant Cell 1995, 7, 1879-1891. [CrossRef]

34. Zhang, Z.-L.; Shin, M.; Zou, X.-L.; Huang, J.-Z.; Ho, T.-H.D.; Shen, Q.-X.J. A negative regulator encoded by a rice WRKY gene represses both abscisic acid and gibberellins signaling in aleurone cells. Plant Mol. Biol. 2009, 70, 139-151. [CrossRef]

35. Wang, H.-M.; Hou, Y.-X.; Wang, S.; Tong, X.-H.; Tang, L.-Q.; Abolore Adijat, A.; Zhang, J.; Wang, Y.-F. WRKY72 negatively regulates seed germination through interfering gibberellin pathway in rice. Rice Sci. 2021, 28, 1-5.

36. Zhang, Z.-L.; Xie, Z.; Zou, X.-L.; Casaretto, J.; Ho, T.-H.D.; Shen, Q.-X.J. A rice WRKY gene encodes a transcriptional repressor of the gibberellin signaling pathway in aleurone cells. Plant Physiol. 2004, 134, 1500-1513. [CrossRef] [PubMed]

37. Li, Q.; Yang, A.; Zhang, W.-H. Higher endogenous bioactive gibberellins and $\alpha$-amylase activity confer greater tolerance of rice seed germination to saline-alkaline stress. Environ. Exp. Bot. 2019, 162, 357-363. [CrossRef]

38. Wang, Y.-L.; Cui, Y.-T.; Hu, G.-H.; Wang, X.-D.; Chen, H.-Z.; Shi, Q.-H.; Xiang, J.; Zhang, Y.-K.; Zhu, D.-F.; Zhang, Y.-P. Reduced bioactive gibberellin content in rice seeds under low temperature leads to decreased sugar consumption and low seed germination rates. Plant Physiol. Biochem. 2018, 133, 1-10. [CrossRef] [PubMed]

39. Hansen, J.; Moller, I. Percolation of starch and soluble carbohydrates from plant tissue for quantitative determination with anthrone. Anal. Biochem. 1975, 68, 87-94. [CrossRef]

40. Chen, M.-L.; Fu, X.-M.; Liu, J.-Q.; Ye, T.-T.; Hou, S.-Y.; Huang, Y.-Q.; Yuan, B.-F.; Wu, Y.; Feng, Y.-Q. Highly sensitive and quantitative profiling of acidic phytohormones using derivatization approach coupled with nano-LC-ESI-Q-TOF-MS analysis. J. Chromatogr. B 2012, 905, 67-74. [CrossRef]

41. He, F.; Zhang, F.; Sun, W.-X.; Ning, Y.-S.; Wang, G.-L. A versatile vector toolkit for functional analysis of rice genes. Rice 2018, 11, 27. [CrossRef] [PubMed]

42. Zhang, Y.; Su, J.-B.; Duan, S.; Ao, Y.; Dai, J.-R.; Liu, J.; Wang, P.; Li, Y.-G.; Liu, B.; Feng, D.-R.; et al. A highly efficient rice green tissue protoplast system for transient gene expression and studying light/chloroplast-related processes. Plant Methods 2011, 7, 30. [CrossRef] [PubMed] 